\title{
Avaliação do Programa Atuação Responsável Quanto à Aplicação do Código de Proteção Ambiental na Indústria de Polímeros
}

\author{
Ana B. A. Santa Marinha, Élen B. A. V. Pacheco \\ Instituto de Macromoléculas Professora Eloisa Mano, UFRJ
}

Geraldo A. T. Fontoura

Bayer S.A

\begin{abstract}
Resumo: Este trabalho teve como objetivo avaliar o Programa Atuação Responsável quanto à aplicação do Código de Proteção Ambiental através de uma pesquisa na indústria petroquímica de segunda-geração, a indústria de fabricação de polímeros. A pesquisa foi realizada por meio de um questionário, endereçado aos responsáveis pela implantação do Programa nas empresas analisadas. Todas são signatárias do Programa Atuação Responsável apresentando alto percentual de implantação das Práticas Gerenciais do Código de Proteção Ambiental.
\end{abstract}

Palavras-chave: Indústria de polímeros, atuação responsável, código de proteção ambiental.

\section{Evaluation of the Program Responsibel Application of the Environmental Protection Code in the Polymer Industry}

Abstract: The purpose of this work is to evaluate the Program "Responsibel Application of the Environmental Protection Code" applied to the polymers production industry, which is a second generation petrochemical industry. The research data was obtained by means of a questionnaire addressed to employees responsible for the implementation of the program. All companies that are involved in this research are participants in the Responsible Care Program, and generally adopt management practices that comply with the Environmental Protection Code.

Keywords: Polymer industry, responsible care.

\section{Introdução}

A população mundial vem crescendo e, para atender às suas necessidades, a indústria petroquímica ampliou sua produção, como outros setores. Entretanto o número de acidentes ambientais que ocorreram em indústrias químicas, de um modo geral, provocando desastres ecológicos e comprometendo a qualidade da vida humana, tornou-se cada vez maior ${ }^{[1]}$. Diante de tais acontecimentos, a sociedade e os governos, principalmente os dos países desenvolvidos, começaram a pressionar o setor industrial. Os governos tomaram algumas medidas para a prevenção de tais acidentes, adotando uma legislação ambiental mais rigorosa.

O Programa Responsible Care, criado no Canadá, em 1985, pela Canadian Chemical Producers Association, foi uma resposta do setor químico para minimizar a ocorrência de acidentes e melhorar a sua imagem. Esse movimento representa um compromisso público e voluntário das empresas com a melhoria nos campos de proteção ao meio ambiente, à saúde e à segurança ${ }^{[2-4]}$.

O Responsible Care está sendo desenvolvido no Brasil desde 1982 pela Associação Brasileira da Indústria Química
-ABIQUIM e foi oficialmente instituído com o nome de Programa Atuação Responsável. Baseia-se em princípios diretivos e utiliza Códigos de Práticas Gerenciais para sua aplicação. As áreas atingidas pelo programa são: Segurança de Processos; Saúde e Segurança do Trabalhador; Proteção Ambiental; Transporte e Distribuição; Diálogo com a Comunidade e Preparação para o Atendimento a Emergências; e Gerenciamento de Produtos ${ }^{[2]}$.

\section{Programa Atuação Responsável}

A estrutura do Programa Atuação Responsável, coordenado pela ABIQUIM, engloba seis elementos básicos: Princípios Diretivos, Códigos de Práticas Gerenciais, Comissões de Lideranças Empresariais, Conselhos Consultivos, Difusão para a Cadeia Produtiva e Avaliação de Desempenho $^{[2,3]}$.

\section{Princípios Diretivos}

Os Princípios Diretivos são padrões éticos que direcionam a indústria química brasileira quanto à saúde, segurança e meio ambiente. São eles ${ }^{[2]}$ :

- Assumir o gerenciamento ambiental como expressão

Autor para correspondência: Élen B. A. V. Pacheco, Instituto de Macromoléculas Professora Eloisa Mano, UFRJ, CT, Bloco J, Cidade Universitária, Ilha do Fundão, CEP:21945-970, Rio de Janeiro, RJ.E-mail: elen@ima.ufrj.br 
de alta prioridade empresarial, por meio de um processo de melhoria contínua em busca da excelência;

- Promover, em todos os níveis hierárquicos, o senso de responsabilidade individual com relação ao meio ambiente, segurança e saúde ocupacional e o senso de prevenção de todas as fontes potenciais de risco associadas às suas operações, aos seus produtos e aos locais de trabalho;

- Ouvir as preocupações da comunidade sobre seus produtos e suas operações e responder a elas;

- Colaborar com órgãos governamentais e não-governamentais na elaboração e aperfeiçoamento de legislação adequada à proteção da comunidade, dos locais de trabalho e do meio ambiente;

- Promover a pesquisa e o desenvolvimento de novos processos e produtos ambientalmente compatíveis;

- Avaliar previamente o impacto ambiental de novas atividades, processos e produtos e monitorar os efeitos ambientais das suas operações;

- Buscar continuamente a redução dos resíduos, efluentes e emissões para o ambiente, oriundos das suas operações;

- Cooperar para a solução dos impactos negativos sobre o meio ambiente decorrentes da disposição indevida de produtos, ocorrida no passado;

- Transmitir às autoridades, aos funcionários, aos clientes e à comunidade informações adequadas quanto aos riscos à saúde, à segurança e ao meio ambiente oferecidos por seus produtos e operações e recomendar medidas de proteção e de emergência;

- Orientar fornecedores, transportadores, distribuidores, consumidores e o público para que transportem, armazenem, usem, reciclem e descartem os seus produtos com segurança;

- Exigir que os empregados contratados, trabalhando nas instalações da empresa, obedeçam aos padrões adotados pela empresa contratante em segurança, saúde ocupacional e meio ambiente;

- Promover os princípios e as práticas do Atuação Responsável, compartilhando experiências e oferecendo assistência a outras empresas para a produção, o manuseio, o transporte, o uso e a disposição de produtos.

\section{Códigos de Práticas Gerenciais}

Os Códigos de Práticas Gerenciais têm por objetivo atender a todas as áreas produtivas e àquelas envolvidas com produtos químicos. Os seis códigos de práticas gerenciais adotados pela ABIQUIM dão suporte à filosofia contida nos princípios diretivos, possibilitando a sua operacionalização. São eles ${ }^{[2-4]}$ :

Segurança de Processos (SEPRO): tem o objetivo de identificar fontes de riscos nas instalações industriais para prevenir acidentes;

Saúde e Segurança do Trabalhador (SST): busca prevenir acidentes envolvendo trabalhadores e contratados da indústria química, através da promoção de condições seguras de trabalho Transporte e Distribuição (TRADI): tem por objetivo minimizar os riscos de acidentes durante o transporte e a distribuição de produtos químicos e agilizar as ações nos casos de emergência;

Proteção Ambiental (PA): tem como objetivo reduzir a geração de efluentes, emissões e resíduos através do aumen- to da eficiência dos processos de fabricação de produtos químicos e do uso de tecnologias limpas.

Diálogo com a Comunidade e Preparação e Atendimento a Emergências (DCPAE): busca ampliar a comunicação com a comunidade interna (trabalhadores) e externa (população próxima à empresa e partes interessadas) e estabelecer a forma de atuar durante situações de emergência nas instalações da indústria química;

Gerenciamento do Produto (GEPRO): serve para garantir que os aspectos relacionados à saúde, à segurança e ao meio ambiente sejam priorizados nas fases de desenvolvimento, produção, manuseio, utilização e descarte de produtos químicos.

\section{Código de Proteção Ambiental}

Este código estabelece que as empresas signatárias do programa Atuação Responsável se comprometem a reduzir a geração de emissões, efluentes e resíduos através da otimização dos processos de produção. Seu objetivo é minimizar os impactos ambientais e maximizar o aproveitamento dos recursos naturais utilizados na produção, por meio da implantação de programas que incentivem a reciclagem, o reuso e a disposição final, sem comprometer o meio ambiente e a comunidade ${ }^{[2-4]}$.

O Código de Proteção Ambiental é constituído por 15 Práticas Gerenciais, as quais foram reagrupadas em 4 elementos, conforme apresenta a Tabela $1^{[4]}$.

Tabela 1. Práticas Gerenciais do Código de Proteção Ambiental ${ }^{[4]}$

\begin{tabular}{|c|c|}
\hline Elementos & Práticas Gerenciais \\
\hline \multirow{2}{*}{$\begin{array}{l}\text { Liderança } \\
\text { Gerencial }\end{array}$} & $\begin{array}{l}\text { Comprometimento e participação } \\
\text { gerencial }\end{array}$ \\
\hline & $\begin{array}{l}\text { Procedimentos para pesquisas e novas } \\
\text { instalações }\end{array}$ \\
\hline \multirow{6}{*}{$\begin{array}{l}\text { Planejamento e } \\
\text { Execução }\end{array}$} & $\begin{array}{l}\text { Inventários de efluentes, emissões e } \\
\text { resíduos }\end{array}$ \\
\hline & Avaliação de impactos ambientais \\
\hline & Prioridade para redução na geração \\
\hline & Redução constante da geração \\
\hline & $\begin{array}{l}\text { Seleção e qualificação de fornecedores } \\
\text { e prestadores de serviços }\end{array}$ \\
\hline & Proteção das águas subterrâneas \\
\hline \multirow{3}{*}{$\begin{array}{l}\text { Verificação e } \\
\text { Execução }\end{array}$} & Medição dos progressos obtidos \\
\hline & Avaliação das práticas operacionais \\
\hline & Análise de práticas passadas \\
\hline \multirow{4}{*}{$\begin{array}{l}\text { Comunicação e } \\
\text { Treinamento }\end{array}$} & $\begin{array}{l}\text { Diálogo com os funcionários e a } \\
\text { comunidade }\end{array}$ \\
\hline & Comunicação de resultados \\
\hline & Redução de resíduos de terceiros \\
\hline & Programa de treinamento \\
\hline
\end{tabular}


O estágio de implantação de cada Código pode ser avaliado através do número de práticas gerenciais que estão sendo incorporadas às práticas da empresa.

\section{Comissões de Lideranças Empresariais}

A execução do Programa Atuação Responsável é direcionada pela Comissão de Lideranças Empresariais, a qual se divide em: Comissões Temáticas e Comissões Setoriais ${ }^{[2]}$.

As Comissões Temáticas são formadas por profissionais das empresas associadas e têm como objetivo acompanhar os principais temas de interesse da indústria química brasileira, promover estudos e propor ações à ABIQUIM. No conjunto das Comissões Temáticas da ABIQUIM, sete temas tratam especificamente do Programa Atuação Responsável: Segurança de Processos, Saúde e Segurança, Meio Ambiente, Transportes, Diálogo com a Comunidade, Atendimento a Emergências, Gerenciamento de Produtos.

As Comissões Setoriais da ABIQUIM representam segmentos específicos cujo objetivo é acompanhar assuntos referentes a elas mesmas. As Comissões Setoriais são as seguintes: Colas, adesivos e selantes, Coplast (resinas termoplásticas), Corantes e pigmentos, Fotoquímicos, Insumos para borracha, Insumos para poliuretanos, Plastivida, Silicones.

\section{Conselhos Consultivos e Comissões de Lideranças Executivas}

Os Conselhos Comunitários Consultivos têm por finalidade estreitar o diálogo entre a indústria química e seus potenciais interessados, estabelecendo um bom relacionamento entre as partes. Os temas importantes ligados ao Programa Atuação Responsável são discutidos de forma aberta nos Conselhos Consultivos, tentando-se obter respostas e soluções efetivas para os problemas levantados ${ }^{[2]}$.

As Comissões de Lideranças Executivas buscam aproximar os representantes das indústrias químicas em nível nacional e regional, discutir e avaliar o Programa Atuação Responsável, trocar experiências e identificar as necessidades do setor.

\section{Difusão para a Cadeia Produtiva}

É a irradiação dos Princípios Diretivos e das Práticas Gerenciais para a cadeia produtiva que compreende empresas transportadoras de produtos químicos, distribuidores ou terminais e empresas de tratamento de resíduos.

\section{Avaliação de Desempenho}

A avaliação de desempenho constitui um indicador para determinar a eficácia da implementação do Programa e as melhorias promovidas pelas empresas nas áreas de saúde, segurança e meio ambiente ${ }^{[2,3]}$.

A Figura 1 apresenta o percentual de implantação das Práticas Gerenciais do Código de Proteção Ambiental nas empresas signatárias da Atuação Responsável. Em 1996, constatou-se, em média, apenas $20 \%$ de implantação das Práticas do Código de Proteção. Em 2000, essa percentagem havia triplicado ${ }^{[2]}$.

Os indicadores de desempenho relativos ao Código de Proteção Ambiental das empresas brasileiras associadas à

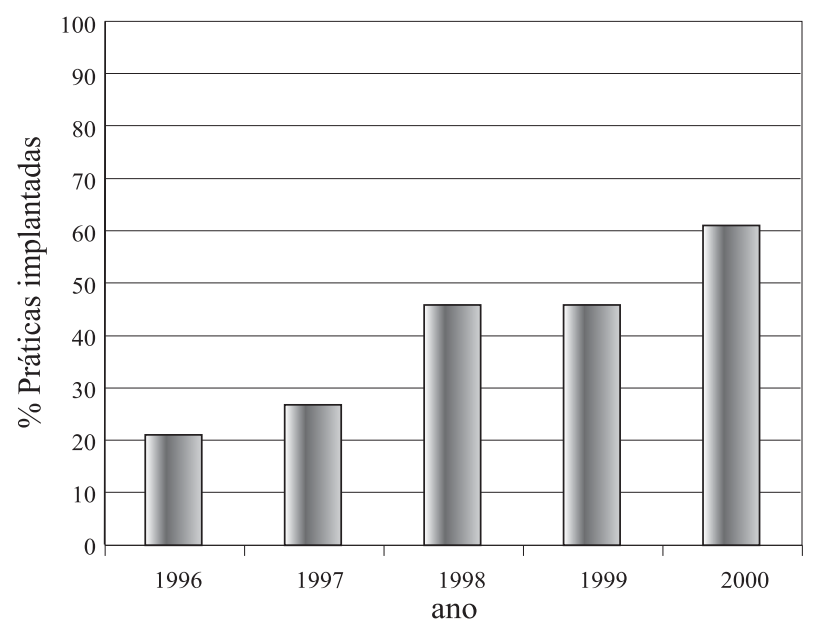

Figura 1. Práticas do Código de Proteção Ambiental implantadas pelas empresas ${ }^{[2]}$

ABIQUIM estão apresentados na Tabela 2. No ano de 1999, foram coletados dados de oitenta e duas empresas e, em 2000, noventa e duas empresas participaram da amostragem ${ }^{[5]}$. Apesar do fato destes indicadores serem aplicados a todos os ramos da indústria química, pode-se considerá-los adequados à avaliação do desempenho do setor de polímeros, tendo em vista as suas características e abrangência.

\section{O Programa Atuação Responsável e as Normas ISO 14000}

O Programa Atuação Responsável, em linhas gerais, é mais amplo do que as normas ISO 14000, pois não se restringe apenas à questão ambiental, abrangendo requisitos relacionados à saúde, à segurança do trabalhador e ao transporte de produtos químicos ${ }^{[4]}$.

Existem, porém, alguns pontos comuns entre as Normas ISO 14000 e o Atuação Responsável ${ }^{[3]}$. Ambos são iniciativas voluntárias que envolvem o apoio e a participação da alta administração. Os dois assumem o cumprimento da legislação ambiental como requisito essencial do Sistema de Gestão Ambiental, promovendo sua melhoria contínua e envolvendo processos e operações. E, por fim, tanto um quanto o outro buscam a identificação dos aspectos e impactos ambientais para priorizar as ações a serem implementadas e o treinamento do pessoal envolvido.

O estudo realizado teve como objetivo avaliar o Programa Atuação Responsável quanto à aplicação do Código de Proteção Ambiental através de uma pesquisa na indústria petroquímica de segunda-geração, a indústria de fabricação de polímeros. Pesquisas sobre o Programa Atuação Responsável no Brasil são poucas $^{[3,6]}$ e não foram encontrados estudos desse Programa na área de polímeros, o que mostra o pioneirismo do trabalho.

\section{Metodologia}

O método utilizado para avaliar a implementação do Atuação Responsável quanto ao Código de Proteção Ambiental nas indústrias de polímeros foi a aplicação de um questionário. Este foi enviado através do correio eletrônico e destinado aos responsáveis pela implementação do programa 
Tabela 2. Indicadores de desempenho relativos ao Código de Proteção Ambiental pesquisados de 1999 a 2002 [5]

\begin{tabular}{|c|c|c|c|c|c|}
\hline \multicolumn{2}{|c|}{ Indicadores de desempenho } & 1999 & 2000 & 2001 & 2002 \\
\hline \multirow{2}{*}{$\begin{array}{l}\text { Geração (para disposição) } \\
\text { de resíduos perigosos e não } \\
\text { perigosos }\end{array}$} & $\mathrm{t}$ & 274.082 & 327.861 & n.d. & n.d. \\
\hline & $\mathrm{Kg} / \mathrm{t}$ de produção & 12 & 12,4 & 10,1 & 8,5 \\
\hline \multicolumn{6}{|l|}{ Emissões gasosas } \\
\hline \multirow{2}{*}{$\mathrm{SO}_{2}$} & $\mathrm{t}$ & 26.068 & 22.906 & n.d. & n.d. \\
\hline & $\mathrm{Kg} / \mathrm{t}$ de produção & 1,1 & 0,9 & n.d. & n.d. \\
\hline \multirow{2}{*}{$\mathrm{CO}_{2}$} & $\mathrm{t}$ & 7.800 .616 & 12.731 .440 & n.d. & n.d. \\
\hline & $\mathrm{Kg} / \mathrm{t}$ de produção & 341,3 & 479,4 & n.d. & n.d. \\
\hline \multicolumn{6}{|l|}{ Efluentes líquidos } \\
\hline Fósforo total & $\mathrm{Kg}$ & 124.986 & 265.854 & n.d. & n.d. \\
\hline Nitrogênio Total & $\mathrm{t}$ & 1.669 & 5.706 & n.d. & n.d. \\
\hline DQO & $\mathrm{t}$ & 38.938 & 23.247 & n.d. & n.d. \\
\hline Metais pesados & $\mathrm{Kg}$ & 25.945 & 23.910 & n.d. & n.d. \\
\hline \multirow{2}{*}{$\begin{array}{l}\text { Volume de efluentes } \\
\text { lançados }\end{array}$} & $\mathrm{m}^{3}$ & 138.090 .122 & 84.031 .006 & n.d. & n.d. \\
\hline & $\mathrm{m}^{3} / \mathrm{t}$ de produção & 6,0 & 3,2 & 3,1 & 3,2 \\
\hline
\end{tabular}

\section{Consumo de recursos naturais}

\begin{tabular}{lccccc}
\hline \multirow{2}{*}{ Energia (elétrica) } & MWh & 26.222 & 24.255 & & \\
& MWh/t de produção & 1,2 & 0,9 & 0,4 & 0,4 \\
\cline { 2 - 6 } Água & $\mathrm{m}^{3}$ & 274.913 .469 & 313.474 .234 & n.d. & n.d. \\
\cline { 2 - 6 } & $\mathrm{m}^{3} / \mathrm{t}$ de produção & 12,0 & 11,8 & 10,4 & 7,2 \\
\hline
\end{tabular}

DQO - Demanda química de oxigênio

n.d. - não divulgado

em 13 empresas petroquímicas de segunda geração, produtoras de polímeros. A escolha destas empresas foi feita a partir da lista de empresas signatárias do Programa Atuação Responsável por ocasião do estudo, tendo sido consideradas as mesmas, as indústrias de polímeros mais expressivas em relação à capacidade de produção.

\section{Resultados e Discussão}

O questionário foi enviado a treze empresas do setor de polímeros, dentre as quais nove responderam a pesquisa, correspondendo a aproximadamente $70 \%$ do total. Este percentual de respostas foi considerado bastante satisfatório.

De acordo com a pesquisa, seis delas são signatárias do Programa Atuação Responsável há mais de dez anos, duas o implantaram entre um a quatro anos e apenas uma aderiu ao programa no período entre cinco a nove anos (Tabela 3 ). Das nove empresas pesquisadas, sete já se encontravam certificadas pela ISO 14001.

Todas as empresas pesquisadas apresentavam de 75 a $100 \%$ das Práticas Gerenciais do Código de Proteção Ambiental implantadas, segundo o critério de auto-avaliação, demonstrando seu grau de comprometimento com o programa.
Tabela 3. Relação entre as empresas pesquisadas, quanto ao tempo de implantação do Atuação Responsável e a certificação ISO 14001

\begin{tabular}{|c|c|c|c|c|c|}
\hline \multirow[b]{2}{*}{ Empresas } & \multicolumn{4}{|c|}{$\begin{array}{l}\text { Tempo de implantação da } \\
\text { Atuação Responsável }\end{array}$} & \multirow{2}{*}{$\begin{array}{c}\text { ISO } \\
14001\end{array}$} \\
\hline & $\begin{array}{l}\text { Mais de } \\
10 \text { anos }\end{array}$ & $\begin{array}{l}5 \text { a } 9 \\
\text { anos }\end{array}$ & $\begin{array}{l}1 \text { a } 4 \\
\text { anos }\end{array}$ & $\begin{array}{c}\text { Menos } \\
\text { de } 1 \\
\text { ano }\end{array}$ & \\
\hline 1 & - & - & $\mathrm{x}$ & - & $\mathrm{x}$ \\
\hline 2 & $\mathrm{x}$ & - & - & - & $\mathrm{x}$ \\
\hline 3 & $\mathrm{x}$ & - & - & - & $\mathrm{x}$ \\
\hline 4 & $\mathrm{x}$ & - & - & - & $\mathrm{x}$ \\
\hline 5 & $\mathrm{x}$ & - & - & - & $\mathrm{x}$ \\
\hline 6 & $\mathrm{x}$ & - & - & - & - \\
\hline 7 & - & $\mathrm{x}$ & - & - & - \\
\hline 8 & - & - & $\mathrm{x}$ & - & $\mathrm{x}$ \\
\hline 9 & $\mathrm{x}$ & - & - & - & $\mathrm{x}$ \\
\hline
\end{tabular}


Das sete empresas pesquisadas certificadas pela ISO 14001, quatro responderam que a implementação do Código de Proteção Ambiental contribuiu muito para o atendimento dos requisitos dessa Norma e três declararam que a contribuição foi de forma razoável. As duas empresas não certificadas pela ISO 14001 acreditam que o Código de Proteção Ambiental pode contribuir de forma significativa para o atendimento dos requisitos da Norma.

O critério adotado para verificação da implementação das práticas gerenciais é a auto-avaliação, uma vez que o processo de avaliação do programa por terceiros, VerificAR, ainda estava em fase de implementação pela ABIQUIM ${ }^{[3]}$. VerificAR é o nome do processo de avaliação da implementação do programa Atuação Responsável por terceiros no Brasil.

A Tabela 4 apresenta a relação comparativa decorrente da pesquisa entre o grau de implementação do Código de Proteção Ambiental e o de outros Códigos, nas empresas pesquisadas. Pode-se observar que a maioria das empresas apresenta maior grau de implantação do Código de Proteção Ambiental (PA) em relação ao Código de Transporte e Distribuição (TRADI) e, ao Código de Diálogo com a Comunidade e Preparo para Atendimento de Emergência (DCPAE).

Já o Código de Saúde e Segurança do Trabalhador (SST) tem, na maioria das empresas, o mesmo grau de implantação do Código de Proteção Ambiental (PA).

Tabela 4. Quantidade de empresas com os seus respectivos graus de implantação do Código de Proteção Ambiental em relação aos dos outros Códigos

\begin{tabular}{|c|c|c|}
\hline Códigos & $\begin{array}{l}\text { Percentual de } \\
\text { implantação do Código } \\
\text { de Proteção Ambiental }\end{array}$ & Empresas \\
\hline \multirow{3}{*}{ SEPRO } & Maior & $1,4,8,9$ \\
\hline & Igual & $2,3,5,6$ \\
\hline & Menor & 7 \\
\hline \multirow{3}{*}{ SST } & Maior & 1 \\
\hline & Igual & $2,3,5,7,9$ \\
\hline & Menor & $4,6,8$ \\
\hline \multirow{3}{*}{ TRADI } & Maior & $1,3,4,5,8,7$ \\
\hline & Igual & 2,9 \\
\hline & Menor & 6 \\
\hline \multirow{3}{*}{ DCPAE } & Maior & $1,3,4,5,7,8,9$ \\
\hline & Igual & 2,6 \\
\hline & Menor & - \\
\hline \multirow{3}{*}{ GEPRO } & Maior & $1,4,5,8$ \\
\hline & Igual & $2,3,6,9$ \\
\hline & Menor & 7 \\
\hline
\end{tabular}

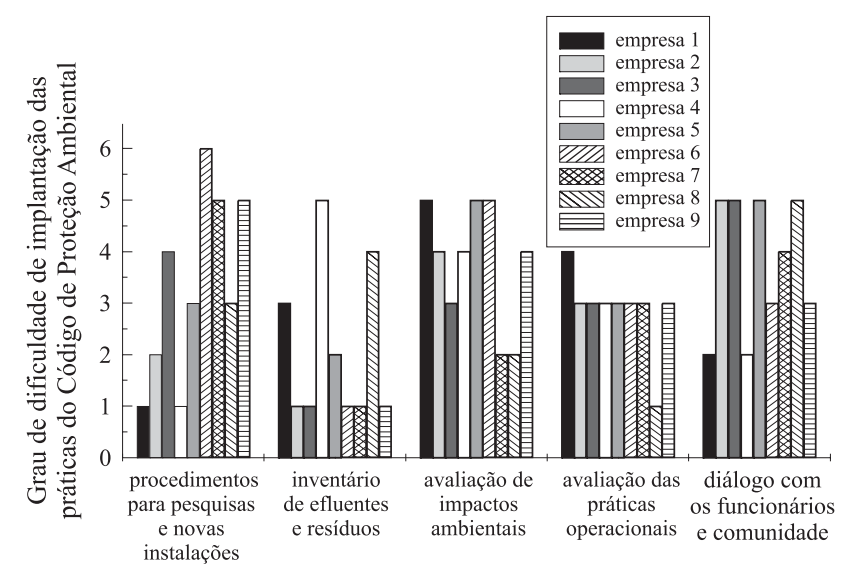

Figura 2. Grau de dificuldade de implementação e de melhoria contínua das Práticas Gerenciais do Código de Proteção Ambiental por empresa

Os Códigos de Segurança de Processo (SEPRO) e de Gerenciamento de Produto (GEPRO) apresentaram, em oito das nove empresas pesquisadas, grau de implementação maior ou igual ao Código de Proteção Ambiental (PA).

Na pesquisa, foram escolhidas cinco Práticas Gerenciais do Código de Proteção Ambiental: Procedimento para pesquisas e novas instalações, Inventário de efluentes e resíduos, Avaliação de impactos ambientais, Avaliação das práticas operacionais e Diálogo com os funcionários e comunidade. Solicitou-se às empresas que relacionassem tais práticas com o grau de dificuldade de implementação e de melhoria contínua. Este grau de implementação recebeu valores de 1 (mais fácil) até 5 (mais difícil) sendo o valor 6 atribuído ao não sabe responder. O resultado está apresentado na Figura 2.

As Práticas consideradas mais difíceis de serem implementadas ou de sofrerem melhorias contínuas foram: o Diálogo com os funcionários e comunidade e a Avaliação de impacto ambiental. A Prática considerada mais fácil, dentre as empresas pesquisadas, foi o Inventário de efluentes, vista como difícil implementação por apenas uma empresa.

A opção "não sabe responder" foi escolhida apenas uma vez, referindo-se à prática Procedimentos para pesquisa de novas instalações.

A Tabela 5 mostra o grau de importância, para as empresas pesquisadas, dos indicadores ambientais. Esses indicadores são avaliados pelas empresas segundo a sua presença na produção. Como exemplo, uma empresa pesquisada não emite fósforo, assim esse indicador não tem grau de importância, foi considerado irrelevante.

Observa-se que três empresas consideraram o "DQO" (Demanda química de oxigênio) como o indicador ambiental mais importante, enquanto duas priorizam a "Geração de resíduos perigosos e não perigosos" e outras duas a "Energia elétrica" .

$\mathrm{O}$ indicador ambiental com menor grau de importância, para cinco empresas, é a emissão de $\mathrm{SO}_{2}$.

Os valores da média ponderada, apresentados na Tabela 5, mostram, portanto, que o "DQO", a "Geração de resíduos perigosos e não perigosos" e a "Água" constituíram os indicadores ambientais mais importantes. 
Tabela 5. Grau de importância dos indicadores ambientais para as empresas pesquisadas e a média ponderada

\begin{tabular}{|c|c|c|c|c|c|c|c|c|c|c|}
\hline \multirow{2}{*}{ Indicador Ambiental } & \multicolumn{9}{|c|}{ Empresa } & \multirow{2}{*}{ Média Ponderada } \\
\hline & 1 & 2 & 3 & 4 & 5 & 6 & 7 & 8 & 9 & \\
\hline $\begin{array}{l}\text { Geração de resíduos perigosos } \\
\text { e não perigosos }\end{array}$ & 3 & 8 & 10 & 7 & 1 & 9 & 10 & 1 & 9 & 6,40 \\
\hline $\mathrm{SO}_{2}$ & 6 & 1 & 6 & 4 & 1 & 1 & 1 & 6 & 1 & 3,00 \\
\hline $\mathrm{CO}_{2}$ & 7 & 2 & 5 & 3 & 5 & 8 & 2 & 7 & 6 & 5,00 \\
\hline Fósforo total & 9 & 4 & 1 & 1 & \# & 5 & 5 & 10 & 3 & 4,75 \\
\hline Nitrogênio total & 10 & 5 & 2 & 2 & 3 & 5 & 4 & 8 & 4 & 4,78 \\
\hline$*$ DQO & 4 & 10 & 3 & 5 & 10 & 5 & 6 & 5 & 10 & 6,56 \\
\hline Metais pesados & 5 & 9 & 7 & 6 & 1 & 5 & 7 & 9 & 2 & 5,76 \\
\hline Volume de efluentes lançados & 8 & 7 & 9 & 8 & 5 & 3 & 8 & 2 & 5 & 5,89 \\
\hline Energia elétrica & 2 & 3 & 4 & 10 & 5 & 10 & 3 & 3 & 7 & 5,22 \\
\hline Água & 1 & 6 & 8 & 9 & 5 & 7 & 9 & 4 & 8 & 6,33 \\
\hline
\end{tabular}

DQO - Demanda química de oxigênio

\# - a empresa não emite fósforo total

\section{Conclusões}

Com base no questionário, concluiu-se que as Práticas Gerenciais do Código de Proteção Ambiental apresentaram um alto percentual de implantação, variando entre 75 a 100\%. Isso ocorreu até mesmo nas empresas que são signatárias entre 1 a 4 anos, caracterizando o comprometimento das mesmas com a proteção do meio ambiente.

A maior parte das empresas pesquisadas são certificadas pela Norma ISO 14001, reconhecendo algumas delas que a implementação do Código de Proteção Ambiental (PA) contribuiu bastante para atender aos requisitos dessa norma.

Observou-se, a partir das respostas dos entrevistados, um maior grau de implementação do Código de Proteção Ambiental em relação ao Código de Transportes e Distribuição e ao Código de Diálogo com a Comunidade e Preparação e Atendimento de Emergência. Em relação aos demais códigos do programa (Segurança de Processos, Gerenciamento de Produtos e Saúde e Segurança do Trabalhador), o Código de Proteção Ambiental foi apontado pelos entrevistados como apresentando grau de implementação igual ou inferior.

A dificuldade de implementação ou de melhoria contínua das Práticas Gerenciais do Código de Proteção Ambiental foi diferenciada para cada uma das empresas. Quatro delas destacaram o "Diálogo com os Funcionários e a Comunidade" como a prática mais difícil.
A importância dada aos indicadores ambientais varia conforme as atividades desenvolvidas pelas empresas, sendo DQO o indicador mais importante para três empresas.

\section{Referências Bibliográficas}

1. Wongtschowski, P., - Indústria Química: Riscos e Oportunidades, Ed.Edgar Blücher Ltda, 2 ed., (1999).

2. Relatório de Atuação Responsável, ABIQUIM - Associação Brasileira da Indústria Química, (2001).

3. Fontoura, G.A.T. - "Responsible Care: Desempenho e Perspectivas do Sistema de Gestão de "Saúde, Segurança e Meio Ambiente" da Indústria Química", Tese de Mestrado, Universidade Federal do Rio de Janeiro, Brasil , (2001).

4. Guia de Implantação - Código de Proteção Ambiental, ABIQUIM - Associação Brasileira da Indústria Química , (1995).

5. Relatório de Atuação Responsável, ABIQUIM - Associação Brasileira da Indústria Química, (2003).

6. Menezes, R.P.B. - “A Indústria Química e a Gestão Ambiental: Dinâmica de Adesão das Indústrias Brasileiras ao Processo de Atuação Responsável”, Tese de Mestrado, Universidade Federal do Rio de Janeiro, Brasil , (1997).

Enviado: $13 / 01 / 04$

Aprovado: 10/07/04 